\title{
Atomistic structure of alkali-silica reaction products refined from X-ray diffraction and micro X-ray absorption data
}

Guoqing Geng ${ }^{1}$, Zhenguo Shi ${ }^{2}$, Andreas Leemann ${ }^{2}$, Camelia Borca ${ }^{3}$, Thomas Huthwelker

${ }^{3}$, Konstantin Glazyrin ${ }^{4}$, Igor V. Pekov ${ }^{5}$, Sergey Churakov ${ }^{1,6}$, Barbara Lothenbach ${ }^{2,7}$, Rainer Dähn ${ }^{1, *}$, Erich Wieland ${ }^{1}$.

${ }^{1}$ Laboratory for Waste Management, Paul Scherrer Institut, 5232 Villigen PSI, Switzerland

${ }^{2}$ Laboratory for Concrete \& Construction Chemistry, Swiss Federal Laboratories for

Materials Science and Technology (Empa), 8600 Dübendorf, Switzerland

${ }^{3}$ Swiss Light Source, Paul Scherrer Institut, 5232 Villigen PSI, Switzerland

${ }^{4}$ Photon Sciences, Deutsches Elektronen-Synchrotron (DESY), D-22603 Hamburg, Germany

${ }^{5}$ Faculty of Geology, Moscow State University, Vorobievy Gory, Moscow, 119991, Russia

${ }^{6}$ Institute of Geological Sciences, University of Bern, Switzerland

${ }^{7}$ Department of Structural Engineering, Norwegian University of Science and Technology,

7491 Trondheim, Norway

${ }^{*}$ Corresponding author. E-mail: rainer.daehn@psi.ch.

\begin{abstract}
The alkali-silica reaction (ASR) causes expansion that lead to severe concrete degradation. The structure of the ASR products remains largely unclear, due to the limitation of laboratory probes in micro-chemical-crystallographic study. We hereby performed synchrotron-radiationbased X-ray absorption spectroscopy and diffraction investigations to both ASR product samples collected from the field, and reference samples with known structure. Our results


suggest that the field ASR crystals from distinct sources are nearly identical. They share a layer-silicate structure similar to the mineral shlykovite, whereas the stacking of the layers in field ASR crystals are altered in several ways, such as the variable basal spacing and significant glide of adjacent layers along the $b$-axis. We also demonstrate that the amorphous ASR product highly resembles C-S-H. Our study adds new insights to the atomistic structure of ASR products.

Keywords: Alkali-Silica Reaction, micro X-ray Absorption Spectra, X-ray Diffraction, Crystal Structure, Shlykovite.

\section{Introduction}

Alkali-silica reaction (ASR) is one of the most detrimental physiochemical processes in concrete that shortens the service life of the infrastructure [1]. This ubiquitous reaction occurs between the reactive siliceous aggregate components and alkaline concrete pore solution that is rich in $\mathrm{K}$ and $\mathrm{Na}$ ions, together with $\mathrm{Ca}$ but in significantly lower concentration. The reaction products have been suggested to uptake water and expand, thus generate internal expansion stress and cracks [1-3]. Historically the ASR product has been described as an amorphous material that is able to flow like a gel, and to swell in the presence of moisture. In the recent few decades, vast microstructural evidences have demonstrated the existence of rather crystalline ASR products with a rosette-like morphology, filling the cracks of the reacted aggregates and/or pore space [4-7]. This immediately challenges the 'gel osmosis expansion' hypothesis, since the source of expansion (cracks inside the aggregate) are populated with crystalline products, rather than amorphous ones.

To further understand the role of crystalline ASR products in the degradation process, their crystal structures need to be resolved. The earlier attempts to decipher the atomistic structure 
of the crystalline ASR products can be classified into two sets of approaches. The first type is to directly investigate the ASR products from affected concrete infrastructure (hereafter denoted as field samples) [4-11]. XRD and SEM-EDX evidences have suggested that the crystalline ASR products may have similar structure as okenite $\left(\mathrm{CaSi}_{2} \mathrm{O}_{5} \cdot 2 \mathrm{H}_{2} \mathrm{O}\right)$ [8], mountainite $\left(\mathrm{KNa}_{2} \mathrm{Ca}_{2}\left[\mathrm{Si}_{8} \mathrm{O}_{19}(\mathrm{OH})\right] \cdot 6 \mathrm{H}_{2} \mathrm{O}\right)$ [5], rhodesite $\left(\mathrm{KHCa}_{2}\left[\mathrm{Si}_{8} \mathrm{O}_{19}\right] \cdot 5 \mathrm{H}_{2} \mathrm{O}\right)$ [5], and the solid solution between mountainite, shlykovite $\left(\mathrm{KCa}\left[\mathrm{Si}_{4} \mathrm{O}_{9}(\mathrm{OH})\right] \cdot 3 \mathrm{H}_{2} \mathrm{O}\right)$ and fedorite $\left((\mathrm{K}, \mathrm{Na})_{2.5}(\mathrm{Ca}, \mathrm{Na})_{7}\left[\mathrm{Si}_{16} \mathrm{O}_{38}(\mathrm{OH}, \mathrm{F})_{2}\right] \cdot 3.5 \mathrm{H}_{2} \mathrm{O}\right)$ [9]. Such studies are often limited by the incomplete isolation of aggregate minerals from pure ASR products, and the uncontrolled alternation of ASR products when exposed to ambient atmosphere. Recent micron-resolved crystal-chemistry studies have significantly improved our knowledge on ASR products [10, 11]. Micro-Raman spectroscopic data suggest that the chemical environment of silica tetrahedral are fairly comparable among ASR crystals from different affected infrastructures and from a concrete subjected to the Norwegian $38{ }^{\circ} \mathrm{C}$ prism test [10]. Recently, Rietveld refinement was conducted using synchrotron micro-XRD data of the same field samples [11]. A satisfactory structural refinement was obtained when starting from a mountainite structure a typical phyllosilicate structure where the main layer is composed of $\mathrm{Ca}$ and $\mathrm{K}$ that are chargebalanced by silicate sheets on both sides [12] (Figure 1a). The interlayer of mountainite is filled with $\mathrm{H}_{2} \mathrm{O}$ and $\mathrm{Na}$. The refinement of field ASR crystals resulted in a rather inter-connected layer-silicate structure in order to explain the strong basal peak at $d \sim 9 \AA$.

The second type of approaches is to investigate the products from a lab-simulated hydrothermal system (hereafter denoted as lab samples) [13-18]. However, most lab-synthesis approaches were hardly helpful for crystal structure refinement of ASR products, since these samples were dominated by C-S-H and/or amorphous silica together with some traces of amorphous ASR products [13-17]. In a recent lab-synthesis approach [18], crystalline products were synthesized at $80^{\circ} \mathrm{C}$ and characterized to be an analog of shlykovite. These synthesized samples are closely 
related to the field ASR crystals according to their highly comparable XRD and micro-Raman results. As a member of the mountainite family, shlykovite has a similar silicate sheet whereas the $\mathrm{K}$ atoms resident in the 8-unit silicate ring instead of in the middle of the main layer as in mountainite [19] (Figure 1b). Protons and/or K exist also in the interlayer to balance the negative charge of silicate sheets.
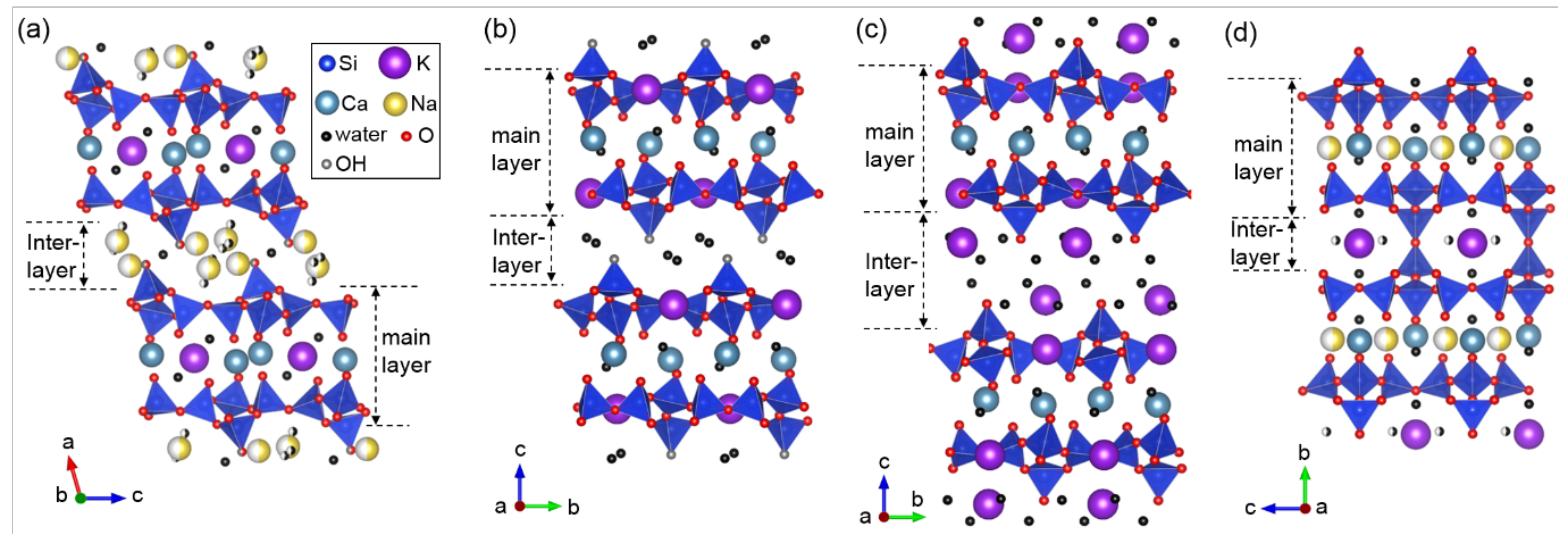

Figure 1. Illustrative crystal structures of (a) mountainite, (b) shlykovite, (c) cryptophyllite and (d) rhodesite. Spheres with partial white color indicate partial occupancy.

Two other minerals, i.e. cryptophyllite $[19,20]$ and rhodesite [21], are also structurally similar to mountainite and shlykovite. As shown in Figure 1c, cryptophyllite and shlykovite have identical main layer structures, yet the interlayer region of cryptophyllite is enriched in $\mathrm{K}^{+}$as charge-balancing cation, which results in a higher content of interlayer water and thus a larger basal spacing. Rhodesite (Figure 1d) has a similar layer silicate structure as the other three minerals, whereas its interlayer is much thinner due to $\mathrm{SiO}_{4}$ tetrahedra crosslinking. The $\mathrm{K}$ and $\mathrm{Na}$ in rhodesite are located in the interlayer and the main layer, respectively. In general, the reported mountainite family minerals have a similar main layer structures, yet they are different in the location and content of charge-balancing $\mathrm{K}$ and $\mathrm{Na}$, and the amount of interlayer water. One significant difference between the previously proposed structure, e.g. kanemite, and the mountainite family is the absence/presence of $\mathrm{Ca}$. The kanemite structure is formed via alternative stacking of silicate tetrahedral sheet and the $\mathrm{Na}(\mathrm{K})$-water polyhedral sheet. No $\mathrm{Ca}$ 
is present in kanemite, which agrees with the chemical composition of the Ca-free gel found often on the surface of affected infrastructures. However, the crystalline ASR product inside the aggregate and the featureless product in the cement paste clearly contain $\mathrm{Ca}$ [10], in better agreement with the mountainite family.

The above evidences have pointed to the possibility of solving the field ASR crystal structure using the structural features of the mountainite mineral family. To validate such similarity for a broader category of ASR field samples, and to solve their crystal structures, this study integrates X-ray micro-spectroscopic and diffraction investigations on several ASR field samples, their natural analogues (i.e. mountainite and shlykovite) and lab-synthesized ASR samples. Chemical environments of $\mathrm{Na}, \mathrm{K}$ and $\mathrm{Ca}$ in these samples were studied by comparing the 'fingerprint' features on the X-ray Absorption Near Edge Structure (XANES) of their $K$ edge spectra. The information was used to modify the shlykovite structure, which was then used as input for a further Rietveld refinement of the XRD data of the crystalline field ASR products.

\section{Methodology}

\subsection{Materials}

Four ASR samples collected in the field were prepared for the micro-XAS study. 'Mels1' is from the abutment of a 50-year-old bridge in Mels, Switzerland. 'ES1' and 'ES2' are from laboratory produced concrete cubes exposed for 14 years to natural conditions in Valencia (Spain) and Milan (Italy), respectively [22]. 'N1' was obtained from a concrete subjected to Norwegian $38{ }^{\circ} \mathrm{C}$ prism test for two years with an expansion of $0.22 \%$ (details available in [10]). The concrete samples were stored in sealed plastic to preserve their initial moisture content before further analysis. Each of the above four samples were dried for three days at 
$50{ }^{\circ} \mathrm{C}$, impregnated with epoxy and polished for the micro-XAS characterization. After the micro-XAS analysis, they were carbon-coated for further SEM-EDX investigations.

Three powder samples of field ASR crystals, denoted as Mels_pore, ES1_agg and ES1_pore, were carefully extracted from the field samples. Mels_pore is extracted from a pore near an aggregate surface, whose source is the same as Mels1. ES1_agg and ES1_pore are extracted crystals from inside an aggregate and from a pore, respectively, from the source of ES1. The extracted powders were sealed in plastic vials immediately after extraction. No intended control of the relative humidity was made, so that the basal spacing of the crystalline field ASR products is studied in natural condition.

The mineral shlykovite was collected from the Rasyumchorr apatite mine in the Khibiny alkaline pluton, Kola Peninsula, Russia, as reported in [20]. The mountainite is also natural. It was collected in the Yubileinaya pegmatite in the Lovozero alkaline pluton, Kola Peninsula, Russia, as described in [14].

In our recent work [18], lab ASR samples were synthesized by mixing $\mathrm{SiO}_{2}, \mathrm{CaO}$ and $(\mathrm{Na} / \mathrm{K}) \mathrm{OH}$ in a molar ratio of 1:0.25:0.5 and at a water-to-solid ratio of 5-10. Obtained solids were filtered and dried after 80 days of reaction at $80^{\circ} \mathrm{C}$. Two of these samples, namely SKC and SNC, were hereby studied as reference phases, since their crystal structure highly resembles that of shlykovite. Another phase synthesized at similar condition was identified as nano-crystalline calcium silicate hydrates $(\mathrm{C}-\mathrm{S}-\mathrm{H})$, yet it has obviously taken up $\mathrm{K}$ as shown later in the results. This sample, hereafter denoted as $\mathrm{K}_{-} \mathrm{CSH}$, is also studied as a reference phase. Details of all samples are summarized in Table 1.

Table 1. General information about the samples. The composition of field samples are the average of $>30$ measurement-points, with a relative uncertainty of $\sim 10 \%$. The $\mathrm{Al}$ content is below $0.4 \%$ and thus ignored in the composition formula for simplicity. The water content of field samples is undetermined and thus represented by an unknown $m$. 


\begin{tabular}{|c|c|c|c|c|}
\hline Sample & Source & & Composition & $\begin{array}{c}\text { Characterization } \\
\text { techniques }\end{array}$ \\
\hline Mountainite & Natural & \multicolumn{2}{|c|}{$\mathrm{Na}_{0.25} \mathrm{~K}_{0.125} \mathrm{Ca}_{0.25} \mathrm{SiO}_{2.375}(\mathrm{OH})_{0.125} \cdot 0.75 \mathrm{H}_{2} \mathrm{O}$} & XAS \\
\hline Shlykovite & Natural & \multicolumn{2}{|c|}{$\mathrm{K}_{0.25} \mathrm{Ca}_{0.25} \mathrm{SiO}_{2.25}(\mathrm{OH})_{0.25} \cdot 0.75 \mathrm{H}_{2} \mathrm{O}$} & XAS \\
\hline $\mathrm{SKC}$ & $\begin{array}{c}\text { Lab synthetic } \\
\text { (shlykovite-like) }\end{array}$ & \multicolumn{2}{|c|}{$\mathrm{K}_{0.25} \mathrm{Ca}_{0.25} \mathrm{SiO}_{2.38} \cdot 0.88 \mathrm{H}_{2} \mathrm{O}$ [23] } & XAS, XRD \\
\hline $\mathrm{SNC}$ & $\begin{array}{c}\text { Lab synthetic } \\
\text { (shlykovite-like) }\end{array}$ & \multicolumn{2}{|c|}{$\mathrm{Na}_{0.25} \mathrm{Ca}_{0.25} \mathrm{SiO}_{2.38} \cdot 0.95 \mathrm{H}_{2} \mathrm{O}[23]$} & XAS, XRD \\
\hline K_CSH & $\begin{array}{l}\text { Lab synthetic } \\
\text { (C-S-H-like) }\end{array}$ & \multicolumn{2}{|c|}{$\mathrm{K}_{0.17} \mathrm{Ca}_{0.30} \mathrm{SiO}_{2.385} \cdot \mathrm{mH}_{2} \mathrm{O}[24]$} & XAS \\
\hline Mels1 & $\begin{array}{l}\text { Core taken from } \\
\text { a Swiss Bridge }\end{array}$ & Crystalline & $\mathrm{Na}_{0.07} \mathrm{~K}_{0.16} \mathrm{Ca}_{0.22} \mathrm{SiO}_{2.335} \cdot m \mathrm{H}_{2} \mathrm{O}$ & $\begin{array}{l}\text { XAS, XRD, } \\
\text { SEM-EDX }\end{array}$ \\
\hline \multirow{2}{*}{ ES1 } & \multirow{2}{*}{$\begin{array}{c}\text { Core taken from } \\
\text { a concrete cube, } \\
\text { Valencia }\end{array}$} & Crystalline & $\mathrm{Na}_{0.11} \mathrm{~K}_{0.2} \mathrm{Ca}_{0.24} \mathrm{SiO}_{2.395} \cdot m \mathrm{H}_{2} \mathrm{O}$ & $\begin{array}{l}\text { XAS, XRD, } \\
\text { SEM-EDX }\end{array}$ \\
\hline & & Amorphous & $\mathrm{Na}_{0.09} \mathrm{~K}_{0.15} \mathrm{Ca}_{0.61} \mathrm{SiO}_{2.73} \cdot m \mathrm{H}_{2} \mathrm{O}$ & $\begin{array}{c}\text { XAS, } \\
\text { SEM-EDX }\end{array}$ \\
\hline \multirow{2}{*}{ ES2 } & \multirow{2}{*}{$\begin{array}{c}\text { Core taken from } \\
\text { a concrete cube, } \\
\text { Milan }\end{array}$} & Crystalline & $\mathrm{Na}_{0.08} \mathrm{~K}_{0.19} \mathrm{Ca}_{0.24} \mathrm{SiO}_{2.375} \cdot m \mathrm{H}_{2} \mathrm{O}$ & \multirow{2}{*}{$\begin{array}{c}\text { XAS, } \\
\text { SEM-EDX }\end{array}$} \\
\hline & & Amorphous & $\mathrm{Na}_{0.14} \mathrm{~K}_{0.16} \mathrm{Ca}_{0.31} \mathrm{SiO}_{2.46} \cdot m \mathrm{H}_{2} \mathrm{O}$ & \\
\hline \multirow{2}{*}{ N1 } & \multirow{2}{*}{$\begin{array}{c}\text { Norwegian } \\
38^{\circ} \mathrm{C} \text { prism test }\end{array}$} & Crystalline & $\mathrm{Na}_{0.08} \mathrm{~K}_{0.18} \mathrm{Ca}_{0.22} \mathrm{SiO}_{2.35} \cdot m \mathrm{H}_{2} \mathrm{O}$ & \multirow{2}{*}{$\begin{array}{c}\text { XAS, } \\
\text { SEM-EDX }\end{array}$} \\
\hline & & Amorphous & $\mathrm{Na}_{0.07} \mathrm{~K}_{0.15} \mathrm{Ca}_{0.39} \mathrm{SiO}_{2.4} \cdot m \mathrm{H}_{2} \mathrm{O}$ & \\
\hline
\end{tabular}

\subsection{SEM-EDX}

The SEM-EDX study was conducted with a FEI Quanta 650 using an acceleration voltage of $12 \mathrm{kV}$, a spot size of 4.5 , a beam current of $\sim 120 \mu \mathrm{A}$ and pressure of $4.0-5.0 \times 10^{-6}$ Torr. Chemical analysis was performed by energy-dispersive X-ray spectroscopy (EDS) with a Thermo Noran Ultra Dry $60 \mathrm{~mm}^{2}$ detector and Pathfinder X-Ray Microanalysis Software. 1030 EDX point measurements were collected on locations corresponding to the ones were XANES measurement were conducted. The values of ASR products of identical morphology were averaged and are shown in Table 1. 


\subsection{Micro X-ray absorption spectroscopy}

The micro-XAS experiments were conducted at the PHOENIX beamline of the Swiss Light Source (SLS). The PHOENIX beamline is an undulator based beamline, operating in the energy range from $0.3-8 \mathrm{keV}$, with options of unfocused $(1.5$ by $1.5 \mathrm{~mm})$ or focused beam (ca. 3 by 3 $\mu \mathrm{m}$ ). Monochromatic light is generated by a double crystal monochromator (Si 111). Powder samples (mountainite, shlykovite, SKC, SNC and K_CSH) were spread on conducting carbon adhesive tapes, and then attached to a copper plate together with the polished field samples. The plate was mounted on a sample stage in a vacuumed chamber $\left(\sim 10^{-5} \mathrm{mbar}\right)$. The X-ray fluorescence signal was recorded using a 4-element energy dispersive silicon drift detector (SDD) manufactured by Vortex. Two-dimensional element mappings were obtained for field samples by scanning the sample through the microfocussed beam with the incident beam energy fixed at $4050 \mathrm{eV}$ (slightly beyond $\mathrm{Ca} K$-edge). The element mappings were compared with SEM images to identity the crystalline and amorphous product regions.

When points of interest (POI) were located, the incident beam energy was scanned to obtain the absorption spectra from 3980 to $4200 \mathrm{eV}$ for $\mathrm{Ca} K$-edge, from 3520 to $3750 \mathrm{eV}$ for $\mathrm{K} K$ edge, and from 1000 to $1200 \mathrm{eV}$ for $\mathrm{Na} K$-edge. Detailed energy scanning parameters are available in Appendix Table 1. The XANES spectra were normalized and processed using the Athena package [25].

\subsection{X-ray powder diffraction}

Powder XRD was conducted at beamline P02.2 at the Deutsches Elektronen-Synchrotron (DESY). To probe the extracted field ASR crystals of very limited quantity, the samples were packed into a cylindrical chamber of $\sim 150 \mu \mathrm{m}$ in diameter and $\sim 70 \mu \mathrm{m}$ in depth, and exposed to an incident beam focused to $8 \mu \mathrm{m} \times 3 \mu \mathrm{m}$. The beam energy was $25450 \mathrm{eV}$, corresponding to a wavelength of $0.4872 \AA$. A PE-XRD1621 image plate was used to collect the diffraction 
data, which was converted to normal diffractogram using the Dioptas package [26]. The $\mathrm{CeO}_{2}$ standard was measured to calibrate the center of the beam on the detector and the sample-todetector distance.

The MAUD package [27] was used for crystal structure analysis, where the instrument broadening parameters were determined by refining the $\mathrm{XRD}$ of $\mathrm{CeO}_{2}$ standard. The reported shlykovite structure is the starting model for analyzing the XRD of ASR-related samples. The lattice parameters and the occupancies of certain atoms were refined. As shown later, the refinement follows a step-by-step manner, with one certain crystal-chemical feature being considered in each refinement step. The anisotropic crystallite size was also refined using a line broadening model implemented in $M A U D$ named "anisotropic - no rules" [27]. The background was modelled by refining a $5^{\text {th }}$ order polynomial.

\section{Results}

\subsection{Micro-XAS}

Concrete affected by ASR reaction possesses characteristic network of cracks and veins from several $\mu \mathrm{m}$ to about $100 \mu \mathrm{m}$ in width (Figure 2 ). Within the boundary of aggregates, the cracks are typically filled with crystalline products of platy morphology, whose thickness is $50-200$ $\mathrm{nm}$. When the cracks approach the surface of the aggregates and run into the cementitious matrix, the morphology of the products become featureless and gel-like. Such a micromorphology is characteristic to the four samples from the field despite their distinct sources. The average chemical composition of the crystalline and the amorphous regions are measured and listed in Table 1. The crystalline regions of the four field samples share similar chemical composition in terms of $(\mathrm{Na}+\mathrm{K}) / \mathrm{Si}(0.23 \sim 0.27)$ and $\mathrm{Ca} / \mathrm{Si}(0.22 \sim 0.24)$. The chemical composition of amorphous regions is more variable for the samples from different locations, yet in general the $\mathrm{Ca} / \mathrm{Si}(0.3 \sim 0.6)$ is clearly higher than that in crystalline regions. Meanwhile, 
the $(\mathrm{Na}+\mathrm{K}) / \mathrm{Si}$ in amorphous regions are similar to that in crystalline regions. Similar results were reported in literature [28], as shown in Figure 2f.

Owing to the distinct $\mathrm{K}$ content in the ASR product and the surrounding materials (aggregate and cementitious paste), the element distribution mapping of $\mathrm{K}$ was used to track the microscale morphology of the samples during the micro-XAS study. As shown in the example of ES2 (Figure $2 \mathrm{a}$ and $2 \mathrm{~b}$ ), the locations of the ASR product in the vein can be determined based on the $\mu$-XRF mapping to the accuracy of $\sim 15 \mu \mathrm{m}$, which is half the pixel size of the element mapping image.
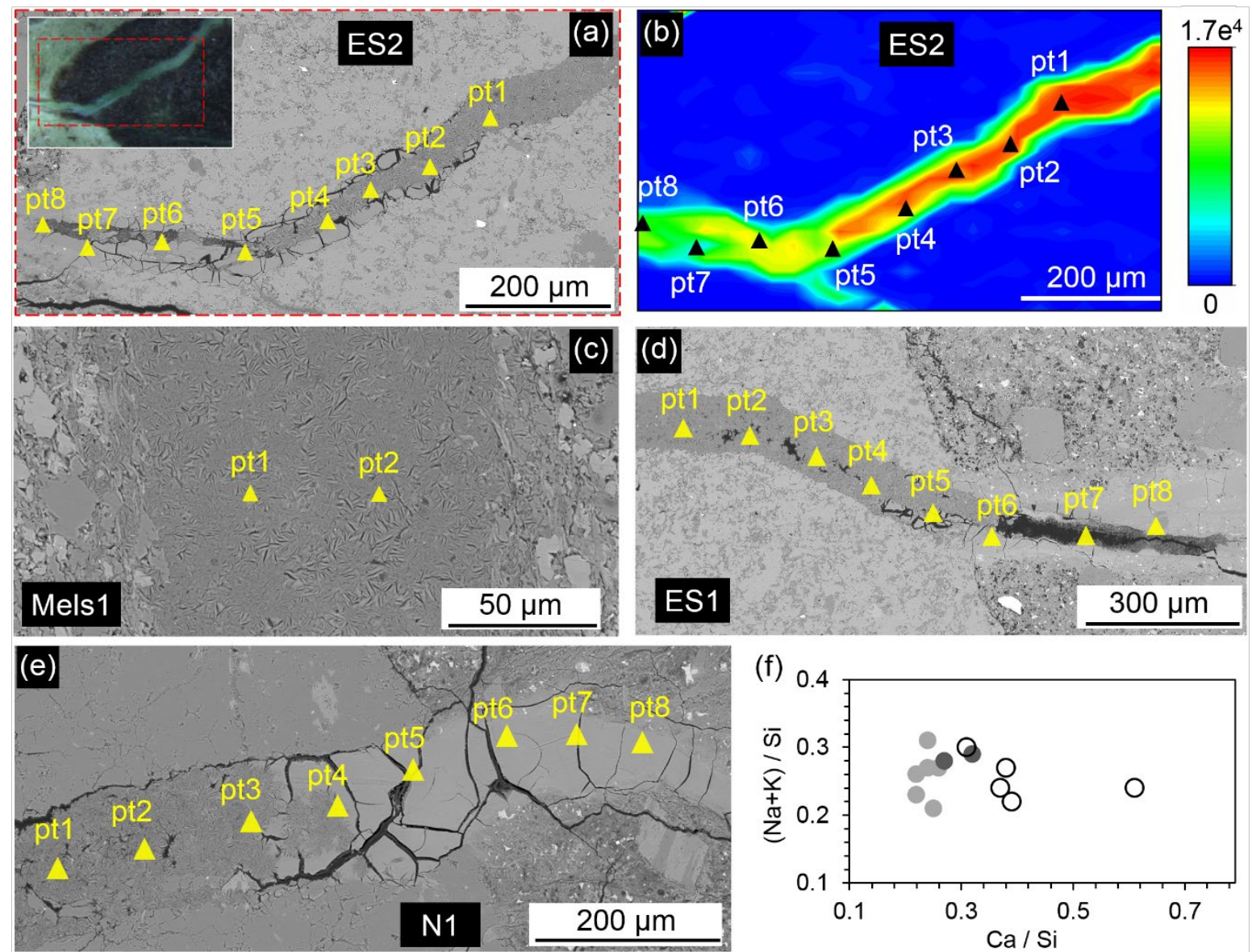

Figure 2. Micro-morphology of crystalline and amorphous products observed in the field samples: (a) an optical and an SEM-magnified image of ES2; (b) XRF mapping of K in (a), with counts/pixel as the intensity; SEM images of (c) Mels1, (d) ES1 and (e) N1. Point of interests labelled with triangles were measured by micro-XAS. (f) The $(\mathrm{Na}+\mathrm{K}) / \mathrm{Si}$ as a function of $\mathrm{Ca} / \mathrm{Si}$ for crystalline (filled spheres) and amorphous regions (open spheres) for this study 
and from published work [28]. Each data point is the averaged value of 20-30 measurements, except for the dark grey spheres where $\sim 100$ measurements were averaged.

The comparative study of XANES is based on the fact that similar XANES spectra often indicate similar chemical environment, since a XANES spectrum contains abundant features that often alter due to a change of neighboring atoms or their coordination geometry [29]. This has been extensively demonstrated for cementitious systems [30-34]. Here, eight points of interests (POIs) were selected for XANES measurements along the veins of ASR products in ES1, ES2 and N1, in a way that the measured spots move from crystalline region to amorphous region, as shown in Figure 2. Only two POIs were selected for the crystalline region in Mels1 due to the difficulty of finding a nearby amorphous region in the studied area. Using the element mapping, it is relatively easy to place a measurement spot on the crystalline product in all four field samples. However, spots of amorphous regions are reliably determined only in sample N1 without an intermix with crystalline phases, whereas in ES1 and ES2 the spots in amorphous regions may include crystalline phases (Figure 2). This will later be demonstrated by the XANES data. For comparing purpose, reference spectra were also measured for shlykovite, mountainite, SKC and K-CSH.

\section{Ca $K$-edge}

The Ca $K$-edge XANES spectra of the field samples are shown in Figure 3a. The spectra have abundant absorption features at both the full multiple scattering (FMS) range (4030 - $4065 \mathrm{eV})$ and the intermediate multiple scattering (IMS) range $(4065-4120 \mathrm{eV})$. The features at the FMS range arise from the characteristic absorption of the center atom to excite its inner shell electrons to the outer shell orbits, and also from the multiple scattering of electromagnetic waves with the surrounding atoms. Therefore it is strongly affected by the type, number and orientation of the ligands surrounding the center atom (here $\mathrm{Ca}$ atom) [35]. The features at the 
IMS range arise mainly from multiple scattering but are less dependent on the neighboring atom shell compared with the features in the FMS range.

It is impractical to label each collected spectrum individually. Instead, the spectra are grouped into three subsets according to the morphology of the measured regions and the similarity/difference in the peak profile. It is readily noted that all the spectra from the crystalline regions are highly comparable, including the Mels1_pt1\&2, ES1_pt1-5, pt7, ES2_pt1-5, and N1_pt1-3. Similarly, the spectra from amorphous regions are nearly identical, including ES2_pt7 and N1_pt5-8. There are measured spots whose crystallinity is not easily determined from the SEM images (Figure 2). Their spectra exhibit features that are observed for both the crystalline and amorphous regions. They are thus considered transition regions that may contain products of both morphologies. Examples include including ES1_pt6\&8, ES2 pt6\&8 and N1 pt4.

In general, the spectra of both crystalline and amorphous products contain multiple peaks. The major peak (peak C) position of the crystalline products is $\sim 1 \mathrm{eV}$ lower than that of the amorphous products, whereas the minor peak (peak $\mathrm{H}$ ) position of crystalline product is $\sim 1 \mathrm{eV}$ higher. A shift of $\sim 0.5 \mathrm{eV}$ is also observed for the position of peak $\mathrm{E}$ and $\mathrm{G}$, between spectra from the crystalline and amorphous regions. In addition, the spectra from the crystalline regions have two extra peaks (C' and D), which are not observed in the spectra of amorphous phases. The intensity of peak C' and D also varies from location to location in the field samples. For example peak C' is more resolvable in ES2_pt3 and Mels1_pt1, but less renowned in ES1_pt1 and N1_pt2. Apart from that, the positions of the pre-edge peak (peak A) and absorption edge (peak B) are comparable for peaks from both regions. Peak F is due to a multi-electron excitation [36], whose intensity and position are comparable among different regions. 

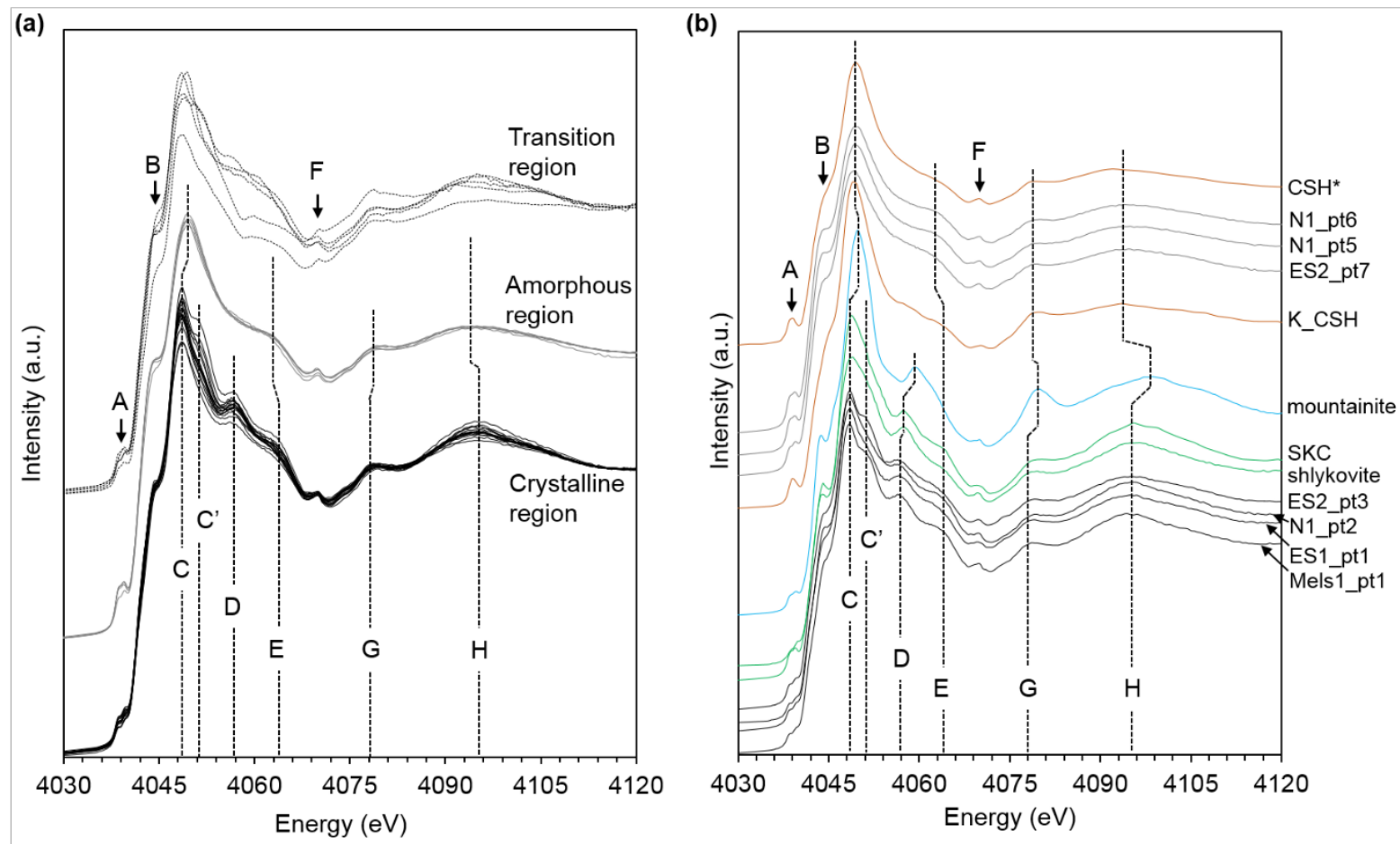

Figure 3. Normalized XANES spectra at the Ca $K$-edge: (a) data for the field samples in crystalline and amorphous regions, and the transitional regions between them; (b) comparisons between the field samples and the reference phases. Data of crystalline, and amorphous regions in the field samples are grouped accordingly. Arbitrary vertical lifts are applied for viewing convenience. Vertical dashed lines are view-guides of peaks whose positions and intensities vary among samples. The spectrum of $\mathrm{CSH}^{*}$ is obtained from literature [37].

In Figure 3b, selected spectra from crystalline (Mels1_pt1, ES1_pt1, ES2_pt3 and N1_pt2) and amorphous regions (ES2_pt7, N1_pt5\&6) are plotted together with the spectra of reference phases. The spectra of the crystalline regions highly resemble the spectra of shlykovite and SKC, with only minor difference that the peak D position in shlykovite and SKC shifts rightward by $\sim 0.7 \mathrm{eV}$. The peak $\mathrm{C}^{\prime}$ in shlykovite and SKC spectra are less renowned and resemble more the spectra of ES1_pt1 and N1_pt2, instead of the spectra of Mels1_pt1 and ES2_pt3. Nonetheless, peak C' clearly present in shlykovite and SKC spectra, judging from the asymmetry of their peak C. Notably, the mountainite spectrum is dissimilar to the spectra of crystalline regions in several aspects. For example, the main peak $\mathrm{C}$ and the minor peaks $\mathrm{D}$, 
$\mathrm{G}$ and $\mathrm{H}$ all shift to the right-hand-side by $1.3-3.0 \mathrm{eV}$. The peak $\mathrm{C}^{\prime}$ and $\mathrm{E}$ are also not clearly observed in mountainite spectrum. This indicates that the chemical environment of $\mathrm{Ca}$ in crystalline field ASR products are highly comparable to that in shlykovite, and different from that of mountainite.

The spectra of amorphous field ASR products are distinct from those of the crystalline products, yet they are highly similar to the spectra of both K_C-S-H, and the published spectrum of an amorphous C-S-H (CSH* in Figure 3b) [37] (Figure 3b). In addition, although not plotted here, the Ca $K$-edge XANES spectrum of $11 \AA$ tobermorite also resembles the spectra of the amorphous ASR product [38]. This suggests that the chemical environment of $\mathrm{Ca}$ in amorphous field ASR products is highly comparable to that in C-S-H and tobermorite, which is represented by two layers of $\mathrm{CaO}_{7}$ polyhedrons with parallel set of silicate dreierketten chains on either sides.

The pre-edge peak $\mathrm{A}$ is due to the $1 s \rightarrow 3 d$ transition, which is a dipole forbidden transition and thus has very low intensity in Ca $K$-edge XANES spectra. For octahedral coordinated $\mathrm{Ca}^{2+}$, its $3 d$ sub-orbitals split into a higher $\left(d_{z^{2}}, d_{x^{2}-y^{2}}\right)$ and a lower energy level $\left(d_{x y}, d_{x z}, d_{y z}\right)$, leading to a split of the peak A [39]. This split is much more pronounced for the $2 p \rightarrow 3 d$ transition peak at $\mathrm{Ca} L_{3,2}$-edge [40]. When the coordination number increases to 7 and/or 8 , the peak A usually becomes several times more intensive due to the loss of octahedral symmetry and the $1 s \rightarrow 3 d$ transition becomes less unfavorable. The split of peak A is also less clear since the energy levels of $3 d$ sub-orbitals become more continuously mixed [39]. As shown in Figure $3 \mathrm{~b}$, the peak A for crystalline regions in field samples exhibit a clear splitting feature related to octahedral symmetry. This is consistent with the first-shell coordination of $\mathrm{Ca}$ in shlykovite and mountainite. Interestingly, the measured peak A of shlykovite is clearly more intensive than the one measured in the field samples, which may suggest a certain degree of disorder in the natural shlykovite sample. As for the amorphous regions, peak A is clearly more intense 
and possesses slight split, resembling that of $\mathrm{CSH}^{*}$. This suggests that $\mathrm{Ca}$ in amorphous regions is coordinated by more than six oxygen atoms, i.e. similar to the intralayer $\mathrm{Ca}$ in the tobermorite structure [41].

\section{K K-edge}

Similar to the $\mathrm{Ca} K$-edge, the $\mathrm{K} K$-edge spectra of micro regions in the field samples are grouped according to the features of their spectra and the morphology of the measured regions (Figure 4a). In general, two major absorption peaks (peak B and C) are observed at the FMS energy range $(3605-3620 \mathrm{eV})$, together with a shoulder (peak A) on the rising part of the spectra. No pre-edge peak is observed on the $\mathrm{K} K$-edge spectra. Several broad peaks are observed at the IMS energy range $(3620-3660 \mathrm{eV})$. The spectra of the crystalline and the amorphous regions are distinguished in two ways. First, the peak B for the crystalline regions are clearly less intensive than peak C. However, in the spectra of amorphous regions the peak B are nearly as intensive as peak C. Second, a minor peak D is observed for the crystalline regions, although its intensity varies from location to location in the field samples. It clearly does not exist in the spectra of the amorphous regions. Apart from these differences, the spectra of both amorphous and crystalline regions are similar in terms of peak positions. 

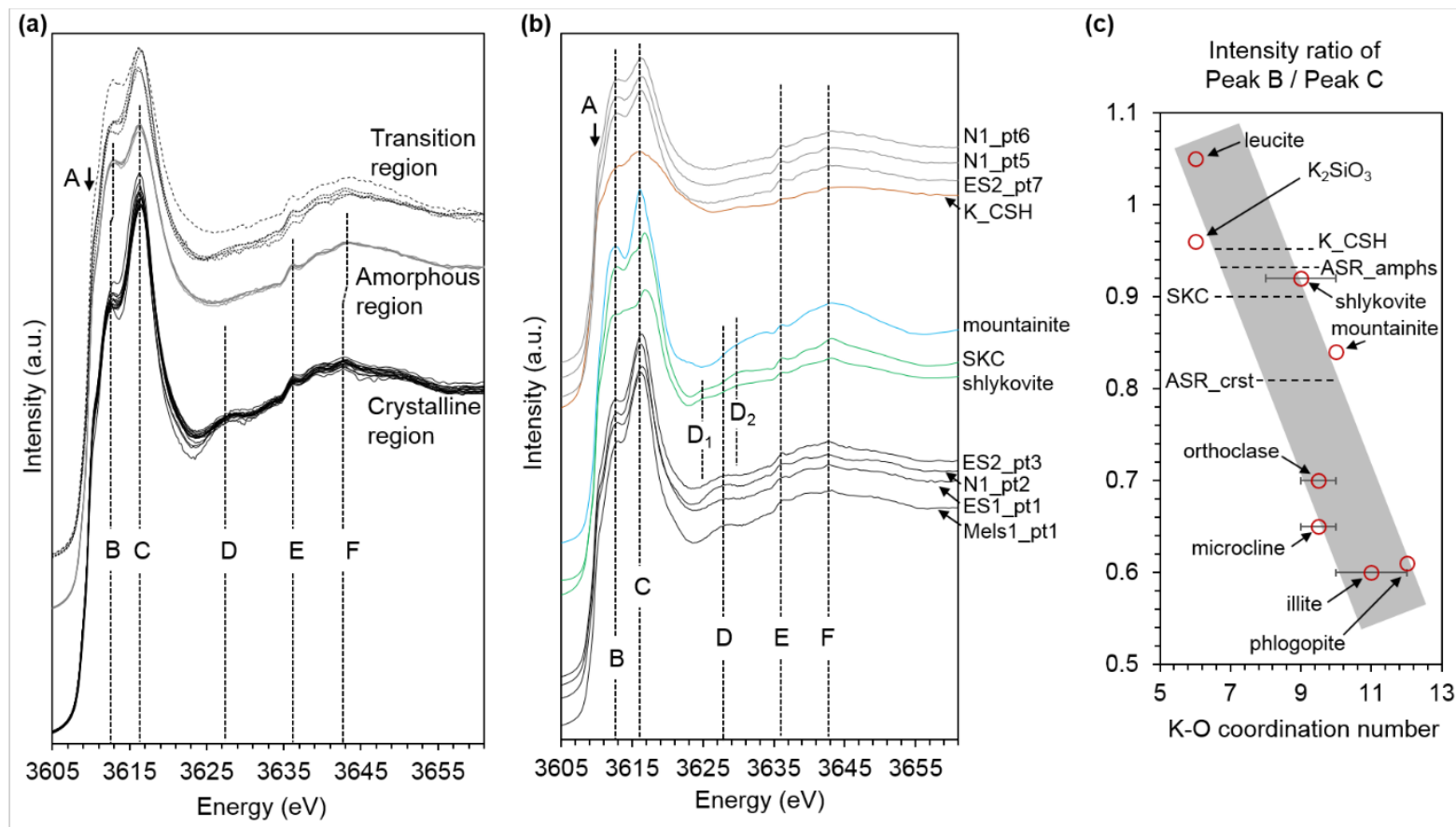

Figure 4. Normalized XANES spectra at the K $K$-edge: (a) data for the field samples in crystalline and amorphous regions, and the transitional regions between them; (b) comparisons between the field samples and the reference phases. (c) The intensity ratio between peak B and $\mathrm{C}$ as a function of the K-O coordination number. Data points of leucite [42], $\mathrm{K}_{2} \mathrm{SiO}_{3}$ [42], orthoclase [43], microcline [44], phlogopite [44] and illite [43] are calculated from the literature. Peak intensity ratios for certain phases are shown in horizontal dash lines when their crystal structures (and K-O coordination number) are not available. The error of the intensity ratio is 0.03 and 0.01 for crystalline ASR (ASR_crst) and amorphous ASR (ASR_amphs) domains, respectively. The grey band is an eye-guide of the trend.

A comparison between the field samples and the reference samples at $\mathrm{K} K$-edge is shown in Figure $4 \mathrm{~b}$. In the FMS energy range, the spectra of shlykovite and SKC are very similar. However, they both seem to be different from the spectra of crystalline regions in field samples, as their peak $\mathrm{C}$ seems to split to a doublet peak. The spectra of mountainite resemble the spectra of crystalline regions in terms of both peak positions and intensities. The relatively large intensity of peak B for the amorphous region does not resemble the feature in the spectra of mountainite and shlykovite. However, it seems to match the spectra of K_CSH. Note that such similarity is also suggested by the Ca $K$-edge spectra. In the IMS energy range, the position 
and intensity of peak E and F are consistent among all studied samples. Compared with the crystalline ASR product, the peak D is shifted and broadened in mountainite. This peak seems to split into two peaks $\left(\mathrm{D}_{1}\right.$ and $\left.\mathrm{D}_{2}\right)$ in shlykovite and SKC. Peak D is not resolved in both amorphous ASR product and K_CSH.

The $\mathrm{K} K$-edge XANES of potassium-bearing silicate minerals have not been as extensively studied as for $\mathrm{Ca} K$-edge. Existing literatures have reported very similar $\mathrm{K} K$-edge spectra for various minerals, in terms of the number of peaks and their positions. The spectra of leucite [42], $\mathrm{K}_{2} \mathrm{SiO}_{3}$ [42], orthoclase [44] and $\mathrm{K}$-micas [44] all exhibit two major absorption peaks in the FMS, i.e. corresponding to the peak B and C in Figure $4 \mathrm{a}$ and $4 \mathrm{~b}$. The most significant difference of the reported $\mathrm{K} K$-edge spectra is the relative intensity of peak B and C. In particular, peak $\mathrm{B}$ is comparable, or even more intensive than peak $\mathrm{C}$ when potassium is coordinated by less than 8 oxygen atoms, e.g. in leucite and $\mathrm{K}_{2} \mathrm{SiO}_{3}$. Whereas peak $\mathrm{C}$ becomes much more dominant when the K-O coordination number is higher than 10, e.g. in K-mica minerals. Such a decreasing trend of intensity ratio between peak B and C, as a function of KO coordination number, is illustrated in Figure 4c. Note in these structures one or two firstshell $\mathrm{O}$ atoms might be located at significantly larger distances from the center $\mathrm{K}$ than the other first-shell O atoms. We therefore count the first shell O with K-O distance longer than $3.4 \AA$ as 0.5 coordination number, with an error of \pm 0.5 .

For ASR-related phases, the trend line suggests a coordination number of $\sim 10 \pm 1$ for $\mathrm{K}$ in crystalline ASR product. In the reported shlykovite structure [20], $\mathrm{K}$ is coordinated by 8-9 O atoms from the 8 -member silicate ring and two $\mathrm{O}$ from water in the main layer and the interlayer, thus matching the intensity ratio of crystalline ASR products. This structure, however, does not well explain the intensity ratio of shlykovite and SKC, where a coordination number of $\sim 9$ is indicated by the trend line. This is very likely due to the splitting of peak $\mathrm{C}$ that reduces its intensity. In fact, all of the published spectra exhibit a single peak $\mathrm{C}$ when there 
is a single $\mathrm{K}$ cite in the structure. Therefore, the splitting peak $\mathrm{C}$ in shlykovite and SKC may indicate presence of two distinct $\mathrm{K}$ environments. In the natural shlykovite sample from the veins may contain intergrowth of cryptophyllite, where one half of $\mathrm{K}$ is 6-coordinated in the interlayer and another half is coordinated identically as in shlykovite [20]. These interlayer K, coordinated by less $\mathrm{O}$ atoms, may explain the splitting of peak $\mathrm{C}$ and the deviation from the trend line. Meanwhile, we do have a clear clue about the splitting of peak C in SKC.

Lastly, the trend line in Figure $4 \mathrm{c}$ suggests a coordination number of $\sim 8 \pm 1$ for $\mathrm{K}$ in amorphous ASR product and K_CSH. It has been proposed recently [45], that K $K$-edge XANES spectrum of ASR product are similar to that of $\mathrm{K}_{2} \mathrm{Si}_{2} \mathrm{O}_{5}$ where $\mathrm{K}$ is coordinated by $7 \mathrm{O}$ atoms [46]. It is likely that the measured bulk sample in the published work [45] contains dominantly amorphous product.

\section{Na $K$-edge}

As shown in Figure 5a, the $\mathrm{Na} K$-edge spectra resemble the features of $\mathrm{K} K$-edge, in terms of the number and position of peaks. There are two dominating peaks (peak B and C) in the FMS energy range $(1070-1090 \mathrm{eV})$, and a few broad features (peak D and E) beyond that range. A weak feature (peak A) is also observed at the rising part of the absorption edge. The $\mathrm{Na} K$-edge spectra of crystalline ASR product are identical among field samples from various sources. This is consistent with the $\mathrm{Ca}$ and $\mathrm{K} K$-edge results that the crystalline products in the field samples are of highly comparable crystal structure, although they form in different concrete mixtures under distinct temperature/moisture histories. This observation applies for amorphous ASR product, as again confirmed by the similarity of $\mathrm{Na} K$-edge spectra of amorphous regions in different field samples.

Unlike the $\mathrm{Ca}$ and $\mathrm{K}$ spectra, the $\mathrm{Na}$ spectra of amorphous and crystalline regions are also comparable with each other (transmission regions thus not determined). The minimal 
difference is highlighted in the inset (red dashed square) in Figure 5a, that the position of peak $\mathrm{B}$ of amorphous regions is $\sim 0.1 \mathrm{eV}$ lower than that of the crystalline regions, whereas the peak $\mathrm{C}$ is $\sim 0.2 \mathrm{eV}$ higher. In addition, there seems to be a weak feature near $1092 \mathrm{eV}$ (peak D) in the spectra of amorphous regions, which is not observed for the crystalline regions. Such a similarity implies that the crystal-chemical environmental of $\mathrm{Na}$ is similar in both crystalline and amorphous regions.
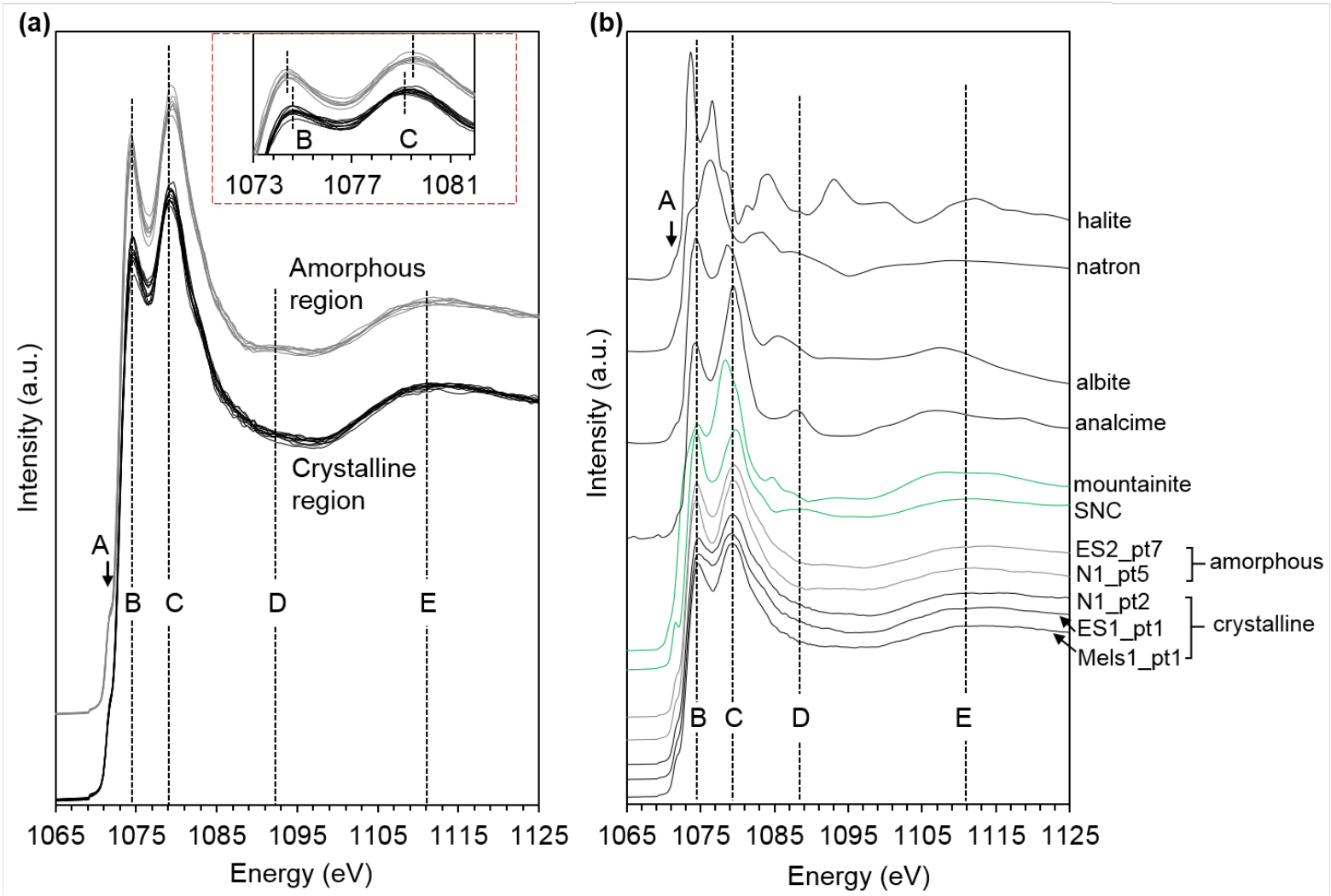

Figure 5. Normalized XANES spectra at the Na $K$-edge: (a) data for the crystalline and amorphous regions in the field samples; (b) comparisons between the field samples and the reference phases. The spectra of halite, natron, albite and analcime are reproduced from literature [47]. Their energy domain is calibrated by aligning the pre-edge peak A to the peak A of the measured spectra here.

Reference spectra of Na-bearing minerals are plotted in Figure 5b, together with the spectra of the field samples. $\mathrm{Na} K$-edge spectra of Na-bearing minerals are not extensively reported, yet the existing results indicate that the type of coordinating ligands is the most dominating factor of the spectral features [47]. For example, the Na $K$-edge spectra of various pyroxenes, 
amphiboles, feldspar and zeolites, where $\mathrm{Na}$ is coordinated by ( $\mathrm{Al}, \mathrm{Si}) \mathrm{O}_{4}$ tetrahedra, are in general very similar, particularly in the FMS range $[47,48]$. Examples of albite $\left(\mathrm{NaAlSi}_{3} \mathrm{O}_{8}\right)$ and analcime $\left(\mathrm{NaAlSi}_{2} \mathrm{O}_{6} \cdot \mathrm{H}_{2} \mathrm{O}\right)$ are shown in Figure $5 \mathrm{~b}$. In comparison, the spectra features are clearly different when $\mathrm{Na}$ is coordinated by $\mathrm{Cl}^{-}$(halite) or $\mathrm{CO}_{3}{ }^{2-}$ (natron). The spectra of both SNC and the field samples clearly exhibit the features of Na-bearing aluminosilicates in the FMS range.

Among the spectra of various aluminosilicate minerals, the most noticeable change is the relative intensity of peak $\mathrm{B}$ and $\mathrm{C}$. However, the ratio is not tightly connected to the coordination number as in the case of $\mathrm{K} K$-edge. For example, $\mathrm{Na}$ is coordinated by six $\mathrm{O}$ atoms in both albite and analcime but of different symmetry, yet peak $\mathrm{C}$ in analcime is more intensive than peak B, but less intensive than peak $\mathrm{B}$ in albite. The symmetry of $\mathrm{Na}$ coordination environment in most aluminosilicate minerals are poorly defined and thus difficult to quantify. Therefore, it is not practical to further link the spectra features of $\mathrm{Na} K$-edge with its coordination environment in aluminosilicate. Nonetheless, the spectrum of mountainite exhibits much stronger peak $\mathrm{C}$ than its peak $\mathrm{B}$, whereas they are equally intensive for SNC where $\mathrm{Na}$ is surrounded by the eight-member silicate ring. The peak $\mathrm{B}$ and $\mathrm{C}$ for the field samples seem to exhibit an averaged feature of mountainite and SNC spectra, in terms of both the relative intensities and the positions. This may suggest that $\mathrm{Na}$ in the field samples exists in both the interlayer region and in the center of the silicate ring.

\subsection{X-ray powder diffraction}

The structure of the crystalline ASR product was further investigated by XRD (Figure 6a), plotted together with the XRD of two lab samples (SKC and SNC) and a theoretically calculated XRD of shlykovite. The XRD of SKC and SNC generally matches that of shlykovite, indicating their comparable crystal structure with slight differences in the lattice parameters 
[7]. The XRD of the crystalline field samples highly resemble each other, indicating a nearly identical structure for crystalline products from different ASR-affected infrastructures (ES1 and Mels) and from different microscale locations (inside aggregates and inside pores of ES1). In general, the XRD of the field samples match that of SKC and SNC, in terms of both the positions and intensity distribution of the most resolved peaks. For example, they all exhibit a dominant basal peak at the low-angle region $\left(1 / d<0.1 \AA^{-1}\right)$, a clear peak at $1 / d \sim 0.15 \AA^{-1}$, a group of diffraction peaks near $1 / d \sim 0.29 \AA^{-1}$ and $0.34 \AA^{-1}$. At the high angle region, two diffraction peaks (marked by red diamond in Figure 6a) are observed in the field samples but not in SKC or SNC. The basal peaks in the field samples are clearly broadened compared with the basal peaks in SKC, SNC and calculated shlykovite XRD, which could be explained by the small crystallite size along the $c$-axis, i.e. perpendicular to the nano-plate. It may also be due to a non-uniform deformation, such as a bending of the nano-platelets along the $c$-axis [49].
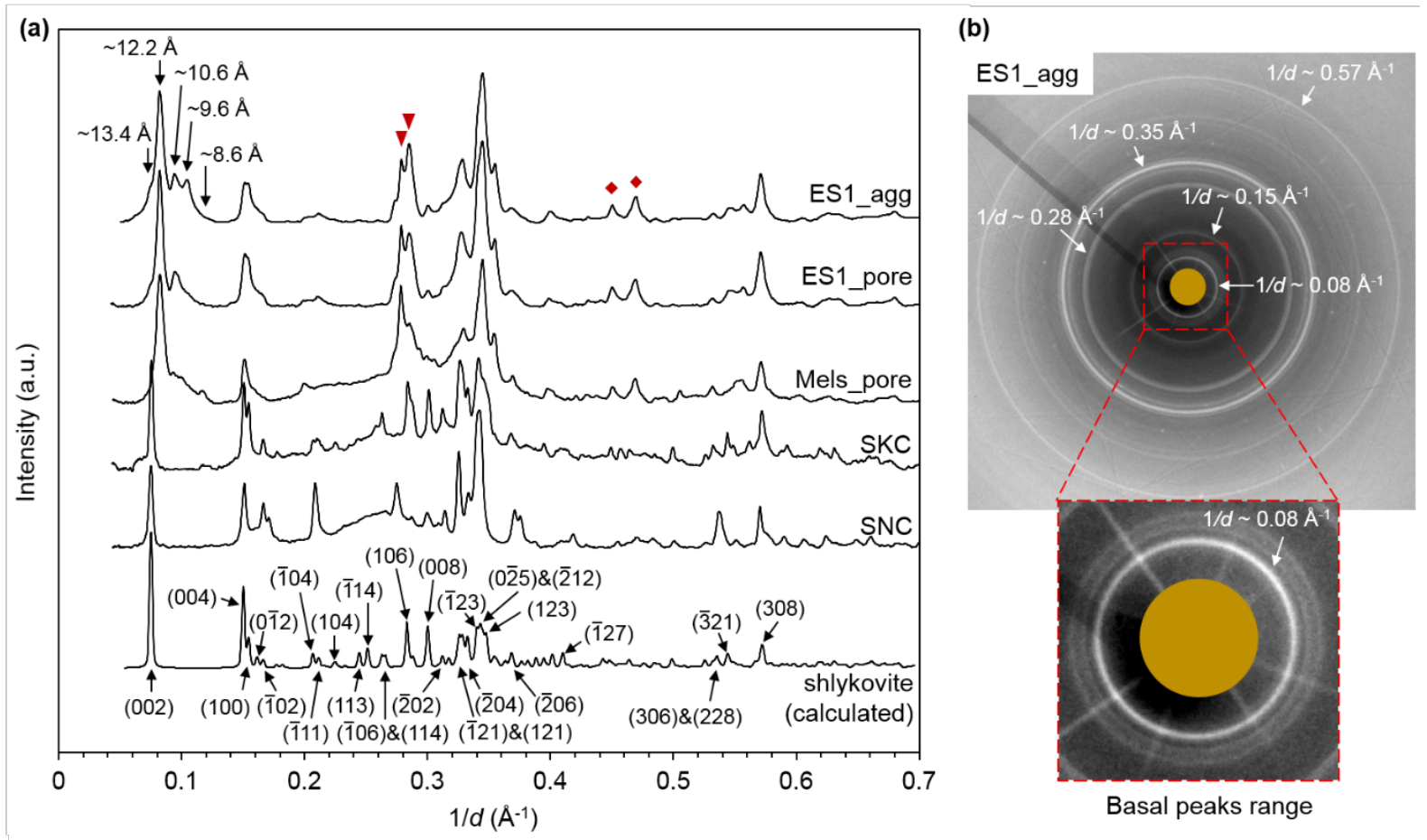

Figure 6. (a) XRD data for crystalline ASR products extracted from the field samples, compared with the XRD of lab samples and the theoretically calculated XRD of shlykovite. 
(b) The 2D raw diffraction image of ES1_agg, with the transmission beam masked by a yellow circle. The red-dashed square is a magnification of the basal peaks range.

Some unique diffraction peaks are observed in the field samples. For example, the intensity ratio between the doublet peaks at $1 / d \sim 0.29 \AA^{-1}$ (marked by red triangle in Figure 6a) varies among different samples. The intensity of the right-hand-side peak in the doublet is higher in ES1_agg, whereas significantly lower in Mels_pore. Unlike the single basal peak in lab samples, multiple basal peaks are observed for the field samples at $1 / d$ ranging from 0.06 to $0.13 \AA^{-1}$, although they share the same dominant basal peak at $d \sim 12.2 \AA$. The intensity of the minor basal peaks also varies among different field samples. As shown in Figure 6a, the ES1_agg has clear minor basal peaks at $d \sim 13.4 \AA$, $10.6 \AA, 9.6 \AA$ and an insignificant peak at 8.6 $\AA$. In ES1_pore, the peak at $d \sim 13.4 \AA$ becomes insignificant. In Mels_pore, all the minor basal peaks become insignificant, yet a broad hump with $1 / d$ ranging from 0.09 to $0.13 \AA^{-1}$ and a peak at $d \sim 8.6 \AA$ are observed. Such a multiple basal peak feature suggests that the crystalline ASR products from the field do not have a unique single structure. Instead, it is a mixture of several phases that share similar shlykovite-like layer structure, but with variable basal spacing ranging from $8.5 \AA$ to $13.5 \AA$. Such a variation in basal spacing is often observed for layer silicates [50] and chain silicates [51] due to the change of interlayer water content.

Rietveld refinement was conducted to further investigate the crystal structure of the field samples. As shown in the raw diffraction image of ES1_agg (Figure 6b), all the diffraction rings have generally homogeneous intensity at all azimuthal angles, suggesting that the grains are randomly oriented inside the chamber. Therefore, a random orientation was considered in the refinement. In addition, to minimize the potential presence of multiple phases, the Mels_pore was used for the detailed XRD analysis, as the minor basal peaks are less obvious in Mels_pore than in the other field samples. The broad basal hump next to the dominant basal peak was accounted by a background peak. Here, we intend to refine the shlykovite structure 
in a stepwise way, with each step considering a crystal-chemical feature suggested by existing results.

First, the XAS results strongly suggest that the $\mathrm{Ca}$ in field samples is in an identical environment as in shlykovite; K may also exist in the same environment as in shlykovite, whereas the location of $\mathrm{Na}$ is not confirmed. Accordingly, the $\mathrm{Ca}$ positions were constrained to be identical to the one in shlykovite model. The $\mathrm{K}$ and $\mathrm{Na}$ were both fixed to the $\mathrm{K}$ position in shlykovite, with partial occupancies being applied ( 0.7 for $\mathrm{K}$ and 0.3 for $\mathrm{Na}$, according to Table 1). The clear drift of the (002) peak indicates a smaller basal spacing in Mels_pore than in shlykovite. Therefore, the interlayer region in Mels_pore model was modified to be $\sim 1.2 \AA$ thinner than that of shlykovite. After considering these features, a theoretical XRD was calculated as shown in Figure 7a Fit_1.
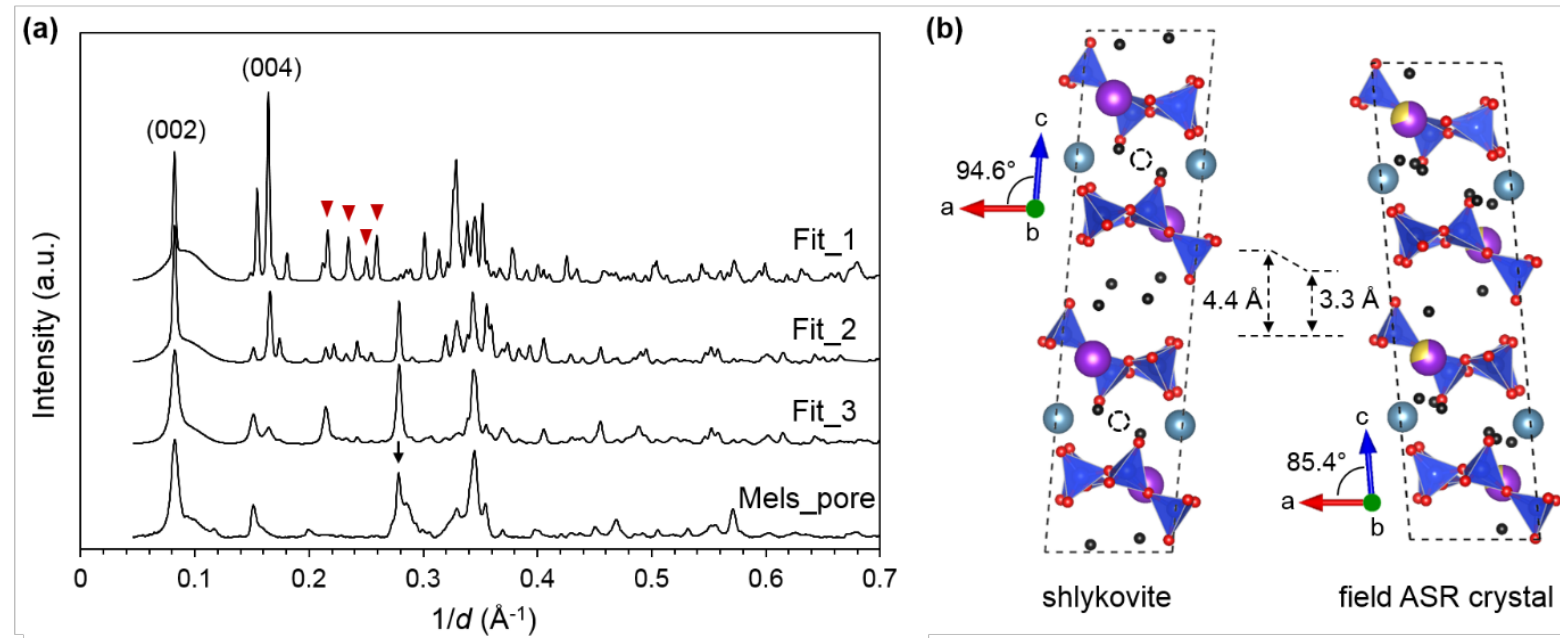

Figure 7. The Rietveld analysis of the ASR crystals from the field. (a) A stepwise refinement of the XRD pattern. (b) A comparison between the crystal structure of natural shlykovite and the field ASR crystal. The red, black, light blue, purple and yellow spheres are oxygen, water, $\mathrm{Ca}, \mathrm{K}$ and $\mathrm{Na}$, respectively. The dashed spheres in shlykovite structure indicate the locations where extra water molecules are placed as initial guess for the refinement. Dashed boxes indicate the unit cell. 
Despite the good match of the (002) basal peak, Fit_1 is clearly not a satisfactory fit for Mels_pore in several aspects. For example, the (004) peak in Fit_1 is overwhelmingly strong, whereas it is not observed in Mels_pore XRD. A set of peaks within $1 / d=0.2-0.26 \AA^{-1}$ are also not observed in Mels_pore, but clearly predicted by Fit_1 (red triangles in Figure 7a). The strong diffraction at $1 / d=0.28 \AA^{-1}$ is observed in Mels_pore (black arrow in Figure 7a), but not in Fit_1. The relative intensities of the peaks with $1 / d$ ranging from 0.32 to $0.36 \AA^{-1}$ are also not properly reproduced in Fit_1. This suggests that, a simple shortening of the interlayer region of shlykovite is insufficient to describe the structure of ASR crystals from the field. Other structural features need to be considered.

In the second step the lattice parameters were refined. The resulted $a, b, c$ and $\beta$ are 6.634(5) $\AA, 6.513(5) \AA, 23.37(3) \AA$ and $85.3(5)^{\circ}$, deviate substantially from the lattice parameters of shlykovite $\left(a=6.4897 \AA, b=6.9969 \AA, c=26.714 \AA\right.$ and $\left.\beta=94.597^{\circ}\right)$. Although constructed of similar layer structure, the unit cell in the field samples is elongated along $a$-axis, but shortened along $b$ and $c$-axis. The $\beta$ angle also decreases by $\sim 9.2^{\circ}$, as illustrated in Figure $7 \mathrm{~b}$. Such a significant shear may suggest a glide between the adjacent layer along the positive and negative direction of $a$-axis. After refining the lattice parameters, the calculated XRD (Fit_2) readily accounts for the major diffraction peaks of Mels_pore.

It is noticed that many diffraction peaks in Fit_2 seem broadened in Mels_pore. To account for this difference, in the third refinement step the anisotropic crystallite size and microstrain was refined. Furthermore, the (004) peak in Fit_2 is still very strong. Note that the (004) peak is an allowed diffraction in the $P 2{ }_{1} / c$ space group. Its absence, in contrast to the strong diffraction of (002), indicates that there is likely a concentration of scatters in the center of each main layer. Indeed the main layer region of shlykovite is much more porous compared with mountainite and rhodesite where $\mathrm{K}$ and $\mathrm{Na}$ occupies the space between $\mathrm{Ca}$ atoms (Figure 1). Therefore, in the third step, water molecules were placed in the center of every four adjacent $\mathrm{Ca}$ atoms, as 
indicated by the dashed sphere in Figure $7 \mathrm{~b}$. Their occupancies and positions were refined. Upon considering these features, the predicted XRD (Fit_3) is a better match of the Mels_pore. Fit_3 addresses the positions and relative intensity of most diffractions, particularly those with strong intensities. The refined amount extra water in the main layer is $\sim 0.78$ times the amount of Si. The refined crystal structure is available in the supplementary material.

Apart from that, a clear diffraction peak is predicted at $1 / d \sim 0.21 \AA^{-1}$ in Fit_3 but not observed in the experiment. The intensities of some minor peaks within $1 / d=0.28-0.36 \AA^{-1}$ are still not properly accounted in Fit_3. These are very likely due to the presence of a different structure with smaller basal spacing in the Mels_pore sample, which contributes to the diffraction in this range but not considered in the theoretical calculation. The variation of other atom positions, such as $\mathrm{Si}, \mathrm{O}, \mathrm{Ca}, \mathrm{K}$ and $\mathrm{Na}$, were not refined here. The thermal displacement parameters were fixed to their original values as in shlykovite (parameter of $\mathrm{Na}$ is from mountainite), without being refined. These may all contribute to the mismatched intensity of minor peaks.

\section{Discussion and conclusions}

The extensive XAS analysis indicates that the various crystalline ASR products from concrete infrastructure are composed of calcium potassium/sodium silicate layers which are structurally highly comparable to the layers in the natural mineral shlykovite. This conclusion is also strongly supported by our previous micro-Raman data $[7,10]$. The XRD of the crystalline ASR products from the field, however, can only be properly accounted for by the shlykovite model after applying substantial structural modifications. For example, the interlayer distance of the dominant phase in the field samples is $\sim 1.1 \AA$ shorter than in shlykovite. It may be even further shortened as indicated by the minor basal peaks in ES1_agg and ES1_pore (Figure 7a). In addition, the refinement of crystalline ASR samples from the field suggests a glide between adjacent layers along the $a$-axis, which significantly reduces the $\beta$ angle by $\sim 9.2^{\circ}$ compared 
with shlykovite. In contrast, the lab-synthesized SKC has a unique basal spacing and its lattice parameters are nearly identical to shlykovite.

The change in the interlayer water content has been well documented to account for the basal spacing variation in many clay minerals $[50,52-54]$. Since the chemical composition and atomistic structure of various field ASR crystals are highly comparable, the basal spacing variation may also suggest a change in the interlayer water content in the field ASR crystals. Such a variation seems always accompanied by a change in the $\beta$ angle. In the clay minerals with swelling ability, the interlayer water content is dominated by the type and content of interlayer cations $[51,54]$. We currently have no data of the interlayer cation contents for ASR crystals with different basal spacing, and thus cannot validate if the variation of interlayer cation type/content is correlated to the changing basal spacing. Such data can be provided using TEM-EDX measurement at the spatial resolution of a single (platy) crystal of crystalline ASR product from the field.

On the other hand, since each main layer of the shlykovite structure is $\sim 9.2 \AA$ thick, the removal of the interlayer water can hardly explain the basal peaks with $d$-spacings smaller than this value. However, basal peaks with $\mathrm{d}<9 \AA$ are observed in Mels_pore (Figure 6a) in our previous micro-XRD study [11] and in other reported data [9]. The shlykovite-like structural model seems not able to explain this basal peak with $d<9 \AA$.

Although the variation of interlayer water content provides possible explanation to the variation of the basal spacing in field ASR crystals, it is still unclear how the basal spacing is related to the external relative humidity (R.H.). This is, however, critical to understand the expansion mechanism of ASR degradation. The internal R.H. of concrete may range within $80 \%-100 \%$ in the first few weeks of hydration [55], and is rarely below $60 \%$ during its service life due to the low permeability of concrete [56]. Future work is needed to investigate the water-uptake behavior of field ASR crystals within this R.H. range. 
Lastly, it should be noted that we intend to minimize the atom position refinement in the XRD analysis here. We only refined the lattice parameters and a few confirmed crystal features to obtain a satisfactory fit to the experimental XRD data. A complete atom position refinement is more practical based on high resolution single phase XRD data. Considering the nanomorphology of the field samples, such data could be obtained on a carefully isolated single piece of field ASR crystal, with a nano-focused X-ray beam. We hereby conclude our main findings as follows.

1. Despite the difference in mixture design and exposure condition, the crystalline ASR products from several affected concrete infrastructures are highly comparable, as indicated by the nearly identical micro-XAS data at $\mathrm{Ca}, \mathrm{K}$ and $\mathrm{Na} K$-edge, and the XRD results. They share a layer-silicate structure that resembles the shlykovite mineral - a monoclinic structure with $P 2{ }_{1} / c$ symmetry.

2. Despite the high similarity between the basic structural units (i.e. calcium potassium/sodium silicate layers), field ASR crystals differ to the natural and labsynthesized shlykovite in the stacking behavior of these units. The basal spacing in the crystalline product of field samples are highly variable, likely due to a variation in the interlayer water content. The adjacent layers in the crystalline product of field samples may glide along the $b$-axis, resulting in a clear change in the $\beta$ angle.

3. The micro-XAS data at $\mathrm{Ca}$ and $\mathrm{K} K$-edge indicate that the amorphous ASR product outside the aggregate boundary is structurally similar to C-S-H.

\section{Author contribution}

Guoqing Geng, Rainer Dähn and Erich Wieland: conceptualization, methodology, investigation, formal analysis, writing. 
Zhenguo Shi, Andreas Leemann, Barbara Lothenbach, Camelia Borca, Thomas Huthwelker and Konstantin Glazyrin: methodology, investigation, writting - review \& editing. Igor V. Pekov and Sergey Churakov: software, resources, writting - review \& editing.

\section{Acknowledgement}

This project is funded by a Swiss SNF Sinergia project: Alkali-silica reaction in concrete (ASR), grant number CRSII5_17108. G. Geng and Z. Shi acknowledge the funding from European Union's Horizon 2020 research and innovation programme under the Marie Skłodowska-Curie grant agreement number 701647 and number 754364. I.V. Pekov acknowledges the funding from the Russian Foundation for Basic Research, grant no. 18-29-12007. We acknowledge the Paul Scherrer Institut, Villigen, Switzerland for provision of synchrotron radiation beamtime at beamline PHOENIX of the SLS. We acknowledge DESY (Hamburg, Germany), a member of the Helmholtz Association HGF, for the provision of experimental facilities. Parts of this research were carried out at beamline P02.2. The authors would like to thank J. Lindgård for providing sample N-1 and A. M. López-Buendía (Aidico), P. Martí Martí (Aidico), E. Menéndez (Eduardo Torroja Institute), A. Santos Silva (LNEC) and J. Custódio (LNEC) for providing the samples ES1 and ES2. Dr. Alla Arakcheeva (EPFL) is acknowledged for the help with the XRD analysis.

\section{Appendix}

Appendix Table 1. The energy scanning parameters for micro-XAS study, eV.

\begin{tabular}{cccccc}
\hline \multicolumn{2}{c}{ Ca $K$-edge } & \multicolumn{2}{c}{ K $K$-edge } & \multicolumn{2}{c}{ Na $K$-edge } \\
Range & Step size & Range & Step size & Range & Step size \\
$3980-4035$ & 5.0 & $3520-3605$ & 5.0 & $1000-1069$ & 5 \\
$4035-4065$ & 0.2 & $3605-3635$ & 0.2 & $1069-1090$ & 0.1 \\
$4065-4120$ & 0.5 & $3635-3680$ & 0.3 & $1090-1130$ & 0.5
\end{tabular}




\begin{tabular}{llllll}
$4120-4200$ & 3.0 & $3680-3750$ & 1.0 & $1130-1200$ & 2.0 \\
\hline
\end{tabular}

\section{References}

1. P.K. Mehta, P.J.M. Monteiro, Concrete: Microstructure, Properties, and Materials, 4th ed., McGraw-Hill Companies, New York City, 2014.

2. B. Fournier, M.A. Bérubé, Alkali-aggregate reaction in concrete: a review of basic concepts and engineering implications, Can. J. Civil Eng. 27 (2000) 167-191.

3. M. Prezzi, P.J. Monteiro, G. Sposito, The alkali-silica reaction: part I. use of the doublelayer theory to explain the behavior of reaction-product gels, ACI Mater. J. 94 (1997) 1017.

4. W.F. Cole, C.J. Lancucki, M.J. Sandy, Products formed in an aged concrete, Cem. Concr. Res. 11 (1981) 443-454.

5. L. De Ceukelaire, The determination of the most common crystalline alkali-silica reaction product, Mater. Struct. 24 (1991) 169-171.

6. A. Fernández-Jiménez, F. Puertas, The alkali-silica reaction in alkali-activated granulated slag mortars with reactive aggregate, Cem. Concr. Res. 32 (2002) 1019-1024.

7. Z. Shi, C. Shi, R. Zhao, S. Wan, Comparison of alkali-silica reactions in alkali-activated slag and Portland cement mortars, Mater. Struct. 48 (2015) 743-751.

8. K. Peterson, D. Gress, T. Van Dam, L. Sutter, Crystallized alkali-silica gel in concrete from the late 1890 s, Cem. Concr. Res. 36 (2006) 1523-1532.

9. T. Katayama, Late-expansive ASR in a 30-year old PC structure in eastern Japan, Proceeding of the 14th International Conference on Alkali-Aggregate Reaction (ICAAR), Austin, USA, 2012.

10. A. Leemann, Raman microscopy of alkali-silica reaction (ASR) products formed in concrete, Cem. Concr. Res. 102 (2017) 41-47. 
11. R. Dähn, A. Arakcheeva, P. Schaub, P. Pattison, G. Chapuis, D. Grolimund, E. Wieland, A. Leemann, Application of micro X-ray diffraction to investigate the reaction products formed by the alkali-silica reaction in concrete structures, Cem. Concr. Res. 79 (2016) 4956.

12. N.V. Zubkova, I.V., Pekov, D.Y. Pushcharovsky, N.V. Chukanov, The crystal structure and refined formula of mountainite, $\mathrm{KNa}_{2} \mathrm{Ca}_{2}\left[\mathrm{Si}_{8} \mathrm{O}_{19}(\mathrm{OH})\right] \cdot 6 \mathrm{H}_{2} \mathrm{O}$, Z. Kristallog. Crystal. Mater. 224 (2009) 389-396.

13. R.J. Kirkpatrick, A.G. Kalinichev, X. Hou, L. Struble, Experimental and molecular dynamics modeling studies of interlayer swelling: water incorporation in kanemite and ASR gel, Mater. Struct. 38 (2005) 449-458.

14. A. Leemann, G. Le Saout, F. Winnefeld, D. Rentsch, B. Lothenbach, Alkali-silica reaction: the influence of calcium on silica dissolution and the formation of reaction products, $\mathrm{J}$. Am. Ceram. Soc. 94 (2011) 1243-1249.

15. X.D. Cong, R.J. Kirkpatrick, S. Diamond, ${ }^{29}$ Si MAS NMR spectroscopic investigation of alkali silica reaction product gels, Cem. Concr. Res. 23 (1993) 811-823.

16. X. Hou, L.J. Struble, R.J. Kirkpatrick, Formation of ASR gel and the roles of CSH and portlandite, Cem. Concr. Res. 34 (2004) 1683-1696.

17. X. Hou, R.J. Kirkpatrick, L.J. Struble, P.J. Monteiro, Structural investigations of alkali silicate gels, J. Am. Ceram. Soc. 88 (2005) 943-949.

18. Z. Shi, G. Geng, A. Leemann, B. Lothenbach, Synthesis, characterization, and water uptake property of alkali-silica reaction products, Cem. Concr. Res. 121 (2019) 58-71.

19. N.V. Zubkova, Y.E. Filinchuk, I.V. Pekov, D.Y., Pushcharovsky, E.R. Gobechiya, Crystal structures of shlykovite and cryptophyllite: comparative crystal chemistry of phyllosilicate minerals of the mountainite family, Eur. J. Mineral. 22 (2010) 547-555. 
20. I.V. Pekov, N.V. Zubkova, Y.E. Filinchuk, N.V. Chukanov, A.E. Zadov, D.Y. Pushcharovsky, E.R. Gobechiya, Shlykovite $\mathrm{KCa}\left[\mathrm{Si}_{4} \mathrm{O}_{9}(\mathrm{OH})\right] \cdot 3 \mathrm{H}_{2} \mathrm{O}$ and cryptophyllite $\mathrm{K}_{2} \mathrm{Ca}\left[\mathrm{Si}_{4} \mathrm{O}_{10}\right] \cdot 5 \mathrm{H}_{2} \mathrm{O}$, new mineral species from the Khibiny alkaline pluton, Kola peninsula, Russia. Geol. Ore Deposit. 52 (2010) 767-777.

21. K.F. Hesse, F. Liebau, S. Merlino, Crystal structure of rhodesite, $\mathrm{HK}_{(1-\mathrm{x})} \mathrm{Na}_{(\mathrm{x}+2 \mathrm{y})} \mathrm{Ca}(2-$ y) $[1 \mathrm{~B}, 3,2(2)]\left[\mathrm{Si}_{8} \mathrm{O}_{19}\right] .(6-\mathrm{z}) \mathrm{H}_{2} \mathrm{O}$, from three localities and its relation to other silicates with dreier double layers, Z. Kristallog. Crystal. Mater. 199 (1992) 25-48.

22. J. Lindgård, Ph. J. Nixon, I. Borchers, B. Schouenborg, B.J. Wigum, M. Haugen, U. Åkesson, The EU "PARTNER" project - European standard tests to prevent alkali reactions in aggregates: final results and recommendations, Cem. Concr. Res. 40 (2010) 611-635.

23. Z. Shi, B. Lothenbach, The role of calcium on the formation of alkali-silica reaction products, unpublished results (submitted) 2019.

24. Z. Shi, B. Lothenbach, The combined effect of potassium, sodium and calcium on alkalisilica reaction products, unpublished results (submitted) 2019.

25. B. Ravel, M. Newville, ATHENA, ARTEMIS, HEPHAESTUS: data analysis for X-ray absorption spectroscopy using IFEFFIT, J. Syn. Rad. 12 (2005) 537-541.

26. C. Prescher, V.B. Prakapenka, DIOPTAS: a program for reduction of two-dimensional Xray diffraction data and data exploration, High Pressure Res. 35 (2015) 223-230.

27. L. Lutterotti, S. Matthies, H.R. Wenk, MAUD: a friendly Java program for material analysis using diffraction, IUCr: Newsletter of the CPD, 21 (1990) 14-15.

28. A. Leemann, P. Lura, E-modulus of the alkali-silica-reaction product determined by micro-indentation, Constr. Build. Mater. 44 (2013) 221-227. 
29. F.E. Sowrey, L.J. Skipper, D.M. Pickup, K.O. Drake, Z. Lin, M.E. Smith, R.J. Newport, Systematic empirical analysis of calcium-oxygen coordination environment by calcium Kedge XANES, Phys. Chem. Chem. Phys. 6 (2004) 188-192.

30. E. Wieland, R. Dähn, M. Vespa, B. Lothenbach, Micro-spectroscopic investigation of Al and S speciation in hardened cement paste, Cem. Concr. Res. 40 (2010) 885-891.

31. B.Z. Dilnesa, E. Wieland, B. Lothenbach, R. Dähn, K.L. Scrivener, Fe-containing phases in hydrated cements, Cem. Concr. Res. 58 (2014) 45-55.

32. G. Geng, R.J. Myers, Y.S. Yu, D.A. Shapiro, R. Winarski, P.E. Levitz, D.A. Kilcoyne, P.J. Monteiro, Synchrotron X-ray nanotomographic and spectromicroscopic study of the tricalcium aluminate hydration in the presence of gypsum, Cem. Concr. Res. 111 (2018) $130-137$.

33. J. Li, G. Geng, R. Myers, Y.S. Yu, D. Shapiro, C. Carraro, R. Maboudian, P.J. Monteiro, The chemistry and structure of calcium (alumino) silicate hydrate: A study by XANES, ptychographic imaging, and wide-and small-angle scattering, Cem. Concr. Res. 115 (2019) $367-378$.

34. B. Ma, A. Fernandez-Martinez, B. Madé, N. Findling, E. Markelova, E. Salas-Colera, T.G. Maffeis, A.R. Lewis, D. Tisserand, S. Bureau, L. Charlet, XANES-based determination of redox potentials imposed by steel corrosion products in cement-based media, Environ. Sci. Tech. 52 (2018) 11931-11940.

35. A. Beran, E. Libowitzky, Spectroscopic Methods in Mineralogy, the Mineralogical Society of Great Britain and Ireland, 2004.

36. J.L. Fulton, S.M. Heald, Y.S. Badyal, J.M. Simonson, Understanding the effects of concentration on the solvation structure of $\mathrm{Ca}^{2+}$ in aqueous solution. I: The perspective on local structure from EXAFS and XANES, J. Phys. Chem. A. 107 (2003) 4688-4696. 
37. X. Guo, J. Wu, Y.M. Yiu, Y. Hu, Y.J. Zhu, T.K. Sham, Drug-nanocarrier interactiontracking the local structure of calcium silicate upon ibuprofen loading with X-ray absorption near edge structure (XANES), Phys. Chem. Chem. Phys. 15 (2013) 1503315040.

38. R.J. Kirkpatrick, G.E. Brown, N. Xu, X. Cong, Ca X-ray absorption spectroscopy of C-S$\mathrm{H}$ and some model compounds, Adv. Cem. Res. 9 (1997) 31-36.

39. V. Martin-Diaconescu, M. Gennari, B. Gerey, E. Tsui, J. Kanady, R. Tran, J. Pécaut, D. Maganas, V. Krewald, E. Gouré, C. Duboc, Ca K-edge XAS as a probe of calcium centers in complex systems, Inorg. Chem. 54 (2014) 1283-1292.

40. G. Geng, R.J. Myers, A.L. Kilcoyne, J. Ha, P.J. Monteiro, Ca L2,3-edge near edge X-ray absorption fine structure of tricalcium aluminate, gypsum, and calcium (sulfo) aluminate hydrates, Am. Miner., 102 (2017) 900-908.

41. S. Merlino, E. Bonaccorsi, T. Armbruster, The real structure of tobermorite 11Å: normal and anomalous forms, OD character and polytypic modifications. Eur.opean Journal of Mineralogy, 13 (2001), pp.577-590.

42. G.P. Huffman, F.E. Huggins, R.W. Shoenberger, J.S. Walker, F.W. Lytle, R.B. Greegor, Investigation of the structural forms of potassium in coke by electron microscopy and Xray absorption spectroscopy, Fuel. 65 (1986) 621-632.

43. C.L. Spiro, J. Wong, F.W. Lytle, R.B. Greegor, D.H. Maylotte, S.H. Lamson,. Forms of potassium in coal and its combustion products, Fuel. 65 (1986), pp.327-336.

44. G. Cibin, A. Mottana, A. Marcelli, M.F. Brigatti, Potassium coordination in trioctahedral micas investigated by K-edge XANES spectroscopy, Mineral. Petrol. 85 (2005) 67-87.

45. R.J. Prado, F. Tiecher, N.P. Hasparyk, D.C.C. Dal Molin, Structural characterization of alkali-silica reaction gel: An x-ray absorption fine structure study. Cem. Concr. Res. 123 (2019) 105774. 
46. B.H.W.S. De Jong, H.T.J. Super, A.L. Spek, N. Veldman, G. Nachtegaal, J.C. Fischer, Mixed alkali systems: structure and ${ }^{29} \mathrm{Si}$ MASNMR of $\mathrm{Li}_{2} \mathrm{Si}_{2} \mathrm{O}_{5}$ and $\mathrm{K}_{2} \mathrm{Si}_{2} \mathrm{O}_{5}$. Acta Crystallograph. B. 54 (1998) 568-577.

47. D.R. Neuville, L. Cormier, A.M. Flank, R.J. Prado, P. Lagarde, Na K-edge XANES spectra of minerals and glasses, Eur. J. Mineral. 16 (2004) 809-816.

48. D.A. McKeown, G.A. Waychunas, G.E. Brown Jr., Exafs and xanes study of the local coordination environment of sodium in a series of silica-rich glasses and selected minerals within the $\mathrm{Na}_{2} \mathrm{O}-\mathrm{Al}_{2} \mathrm{O}_{3}-\mathrm{SiO}_{2}$ system, J. Non-Cryst. Solids. 74 (1985) 325-348.

49. A.k. Zak, W.A. Majid, M.E. Abrishami, R. Yousefi, X-ray analysis of ZnO nanoparticles by Williamson-Hall and size-strain plot methods, Solid State Sci. 13 (2011) 251-256.

50. T.J. Tambach, P.G. Bolhuis, E.J. Hensen, B. Smit, Hysteresis in clay swelling induced by hydrogen bonding: accurate prediction of swelling states, Langmuir, 22 (2006) 1223-1234.

51. C. Biagioni, E. Bonaccorsi, S. Merlino, D. Bersani, New data on the thermal behavior of $14 \AA$ Å tobermorite, Cem. Concr. Res. 49 (2013) 48-54.

52. R.L. Anderson, I. Ratcliffe, H.C. Greenwell, P.A. Williams, S. Cliffe, P.V. Coveney, Clay swelling - a challenge in the oilfield, Earth-Sci. Rev. 98 (2010) 201-216.

53. S.V. Churakov, G. Kosakowski, An ab initio molecular dynamics study of hydronium complexation in Na-montmorillonite, Philos. Mag. 90 (2010) 2459-2474.

54. S.V. Churakov, Mobility of $\mathrm{Na}$ and $\mathrm{Cs}$ on montmorillonite surface under partially saturated conditions, Environ. Sci. Tech. 47 (2013) 9816-9823.

55. Z. Hu, M. Wyrzykowski, K. Scrivener, P. Lura, A novel method to predict internal relative humidity in cementitious materials by ${ }^{1} \mathrm{H}$ NMR, Cem. Concr. Res. 104 (2018) 80-93.

56. C. Andrade, J. Sarría, C. Alonso, Relative humidity in the interior of concrete exposed to natural and artificial weathering, Cem. Concr. Res. 29 (1999) 1249-1259. 